\title{
ОСОБЕННОСТИ ПРОЯВЛЕНИЯ САМОСТОЯТЕЛЬНОГО И ОТВЕТСТВЕННОГО ПОВЕДЕНИЯ МЛАДШИМИ ШКОЛЬНИКАМИ С ИНТЕЛЛЕКТУАЛЬНОЙ НЕДОСТАТОЧНОСТЬЮ, В УСЛОВИЯХ ЗАДАННОЙ СИТУАЦИИ
}

\section{FEATURES OF THE MANIFESTATION OF INDEPENDENT AND RESPONSIBLE BEHAVIOR BY PRIMARY SCHOOL STUDENTS WITH INTELLECTUAL DISABILITIES, IN A GIVEN SITUATION \\ Yu. Feoktistova}

Summary: The article presents the results of an experimental study of the manifestations of social responsibility and socially responsible behavior of children with intellectual disabilities. The author compares the manifestations of socially responsible behavior of younger schoolchildren with intellectual disabilities and their normally developing peers.

Keywords: social responsibility, socially responsible behavior, independence, primary school students, intellectual disability, mental retardation.
B опрос подготовки подрастающего поколения к самостоятельной жизни, к возможностям обретения детьми и подростками социально ответственной позиции по отношению к себе и окружающим, к окружающей среде всегда был и остается важным в нашей общественной жизни. В связи с событиями, происходящими в стране и мире, эта проблема становится особенно актуальной, значимость воспитания в детях социальной ответственности, социально ответственного поведения сегодня как никогда осознается не только педагогами, но обществом в целом.

Под социальной ответственностью мы понимаем осознанное понимание личностью целей и задач, стоящими перед обществом, следование общепринятым нормам и правилам, соблюделние при этом, интересов и ценностей своей группы, общества в целом, самостоятельный выбор путей их реализации, умение предвидеть последствия своих поступков и нести за них ответственность перед обществом и самим собой, все это обеспечивает порядок и спокойствие в современном обществе.

Социальная ответственность обнаруживает себя в социально ответственном поведении человека. В основе психологической природы социально ответственного поведения лежит сложный механизм взаимодействия
Феоктистова Юлия Сергеевна

аспирант, РГПУ им. А.И. Герцена; психолог, ЦВЛ «Детская психиатрия» им.С.С. Мнухина, г. Санкт-Петербург

yulla13@mail.ru

Аннотация: В статье представлены результаты экспериментального изучения проявления социальной ответственности и социально ответственного поведения детей с интеллектуальной недостаточностью. Проводится сравнение проявлений социально ответственного поведения младших школьников с интеллектуальной недостаточностью и их нормально развивающихся сверстников.

Ключевые слова: социальная ответственность, социально ответственное поведение, самостоятельность, младшие школьники, интеллектуальная недостаточность, умственная отсталость.

нескольких факторов, которые включают единство индивидуального физического, социального и психического развития личности.

Чувство ответственности - это характеристика зрелой личности. Но закладывается оно в детские годы в повседневной жизни, в отношениях со значимыми взрослыми и сверстниками, в которых ребенок получает первый и важный опыт социально ответственного поведения. Феномен социальной ответственности может рассматриваться как составляющая сознания, формирующаяся в ходе личностного развития ребенка в результате присвоения и усвоения детьми образцов поведения, социальных норм и ценностей, представлений о добре и зле, позволяющих ему успешно функционировать в обществе. Это дает основание говорить о сложной структуре такого феномена психики как социальная ответственность, в основе которой лежит мотивационный компонент, позволяющий выявить стремление к проявлению самостоятельности и личной добровольной активности ребенка при выполнении какой-либо деятельности.

Становление мотивационного компонента определяется отечественными психологами Л.А. Венгером, Л.И. Дементий, Л.И. Божович, как «качество личности, приобретаемое в процессе социализации, которое вы- 
ражается в осознании и эмоциональном переживании необходимости выполнения дела, имеющего значение не только для себя лично, но и для других людей, готовности дать отчет за свои действия, за невыполнение деятельности, в том числе и общественно значимой» $[2,3,1]$. Исходя из этого, можно говорить о том, что мотивационный компонент социальной ответственности поддерживается эмоциональным переживанием и обусловливает соответствующее поведение и деятельность ребенка, которые проявляются в принятии на себя задания и его самостоятельном выполнении.

Таким образом, можно утверждать, что самостоятельность и ответственность - это взаимозависимые категории. По мнению К. Муздыбаева «только тогда, когда решение принято лично самим субъектом действий, на него ложится вся ответственность» [5]. Известно, что выполняя какую-либо деятельность самостоятельно, человек сам принимает решения, проявляет инициативу, находит способы для достижения целей деятельности, воплощает решения в действительность, отвечает за результаты своей деятельности.

Экспериментальные исследования К.А. Климовой, Т.В. Морозкиной, Т.Н. Сидоровой, Л.С. Славиной свидетельствуют о том, что формирование ответственного отношения к порученным обязанностям и их исполнение берет свое начало еще в дошкольном возрасте $[8,10,11]$. По их мнению, уже к пяти годам через длительную тренировку воли и характера ребенка, при осуществлении совместной деятельности с другими детьми и взрослыми, он усваивает правила коллективной жизни, несмотря на то, что эти правила пока недостаточно им осознаны.

Наиболее важным возрастным периодом для формирования осознанного социально ответственного поведения выделяется младший школьный возраст. Главным психологическим новообразованием младших школьников выступает произвольность психических процессов, формируются регуляторные и волевые механизмы, называемые процессом саморегуляции. В качестве основного механизма формирования социальной ответственности в младшем школьном возрасте выступает сформировавшаяся внутренняя позиция, способность быть объективным - особое ценностное отношение ребенка к себе, окружающим, различным аспектам социальной действительности [7].

Все младшие школьники проходят кризис 7-ми лет, когда в ребенке одновременно сочетаются черты дошкольного детства с особенностями школьника. Переоценка ценностей ведет к перемене самосознания ребенка. Те моменты, которые в жизни дошкольников играли большую роль, сейчас отходят на второй план. Предыдущие мотивы уже не имеют побудительной силы, на смену им приходят новые. В семь лет ребенок уже приобретает способность критически относиться к своему поведению и может понять и принять точку зрения других.

Все вышеперечисленные изменения связаны с началом систематического обучения ребенка в школе, которое меняет не только социальную ситуацию развития ребенка, но и его социальный статус. Освоение структуры нового вида деятельности, переход к иной социальной позиции обусловливает необходимость формирования у младшего школьника ответственности за свои действия как способности осуществлять самостоятельный выбор и контроль за его реализацией в конкретных социальных ситуациях [12].

В этот возрастной период такая составляющая личностного развития как социальная ответственность приобретает особую актуальность в условиях современной ситуации в системе образования, ориентированной на реализацию технологии безотметочного обучения, когда младшие школьники призваны самостоятельно контролировать успешность своей учебной деятельности. Успешность в учебной деятельности в этом случае попадает под прямую зависимость от способности ребенка вести себя ответственно, от того, как он себе эту ответственность представляет.

Известно, что самые первые навыки социального опыта ребенок приобретает в своей семье, где происходит выработка и принятие системы ценностей, общественных норм и правил. Будучи членом семьи, вступая в определённые отношения с родителями, ребенок приобретает первый опыт социальной ответственности: связанный с личными вещами и игрушками, сохранением достойного внешнего вида, понимает важность бережного отношения к природе и вещам, принадлежащим другим, имеет начальные представления о собственной ответственности за здоровье.

С имеющимися представлениями о социальной ответственности ребенок приходит в первый класс, где перед младшим школьником выдвигается целый ряд новых требований: ходить в школу, выполнять требования учителя, следовать школьному режиму, подчиняться правилам поведения, выстраивать отношения с одноклассниками.

В условиях современного мира неуклонно и стремительно растут требования государства и общества к проявлению личной социальной ответственности у людей. Возросла роль отдельного человека в общественной жизни, расширились его свобода и в то же время зависимость от внешней социальной среды. Социальная ответственность все больше становится залогом успешности функционирования личности.

Это требование общества не может не коснуться и 
коррекционных школьных образовательных организаций, одной из основных задач которых является социальная адаптация и подготовка к самостоятельной жизни ее выпускников. Успешность подготовки школьников с интеллектуальными нарушениями к самостоятельной жизни в обществе зависит не только от приобретения ими определенных знаний по общеобразовательным предметам и профессионально-трудовой деятельности, но и от уровня сформированности навыков социальной ответственности.

Любой человек как социальное существо, выступает субъектом взаимодействия с другими людьми, и всегда несет личную ответственность за результат этого взаимодействия. В связи с этим возникает необходимость изучения проблемы социальной ответственности в отношении тех подрастающих членов нашего общества, чье развитие проходит в условиях интеллектуальной депривации, что создает определенные трудности в ходе формирования у них ответственности за свои действия, слова, поступки.

Для оценки способности детей к проявлению самостоятельного и ответственного выполнения задания по просьбе была использована методика

«Задание с пятницы на понедельник», разработанная М.В. Матюхиной, С.Г. Яриковой [12].

Эксперимент проводился в течение 2014-2016 года на базе образовательных учреждений города СанктПетербурга: ГБОУ школа №34 и ГБОУ школа-интернат №18 Невского р-на (Специальные (коррекционные) школы), ГБОУ школа №20 Невского р-на, ГБОУ школа № 236 Фрунзенского р-на (общеобразовательные школы), В исследовании приняли участие 120 школьников 8-10 лет: из них 40 младших школьников с легкой умственной отсталостью (УО), 40 младших школьников с задержкой психического развития (3ПР), а также 40 сверстников с нормальным интеллектуальным развитием (H).

В пятницу детям было предложено выполнить задание к понедельнику: принести к занятию журналы или газеты для проведения совместной игры, при этом не акцентировалось внимание испытуемых на записи этого задания в дневнике. Важно заметить, что все дети проявили активный интерес, настойчиво спрашивали: «Зачем нужно принести журналы, газеты», «Подойдут ли такие, какие есть дома» (описывали их), «Сколько их нужно принести», получали объяснение и с радостью говорили о том, что обязательно принесут.

В результате количественного анализа результатов выполнения задания, испытуемые разделились на три группы:

1. те, кто выполнил задание в срок;

2. те, кто выполнил задание на следующий день;

3. те, кто не выполнил задание.

Полученные количественные данные отражены в гистограммах на Рисунке 1 и 2.

Анализ данных показывает, что в срок выполнили задание представители всех групп детей, участвующих в эксперименте (рис.1). Среди умственно отсталых детей таких оказалось 25\%, среди учащихся младшего школьного возраста дети с задержкой психического развития - 20\%, среди нормально развивающихся детей - также $20 \%$.

Как видно из графика на рисунке 2, наибольший процент выполнивших в срок задание составили второклассники контрольных групп (КГ1 (ЗПР) - 30\% и КГ2 (Н) 25\%), среди детей экспериментальной группы (УО) таких оказалось только 15\%. К третьему классу проявление са-

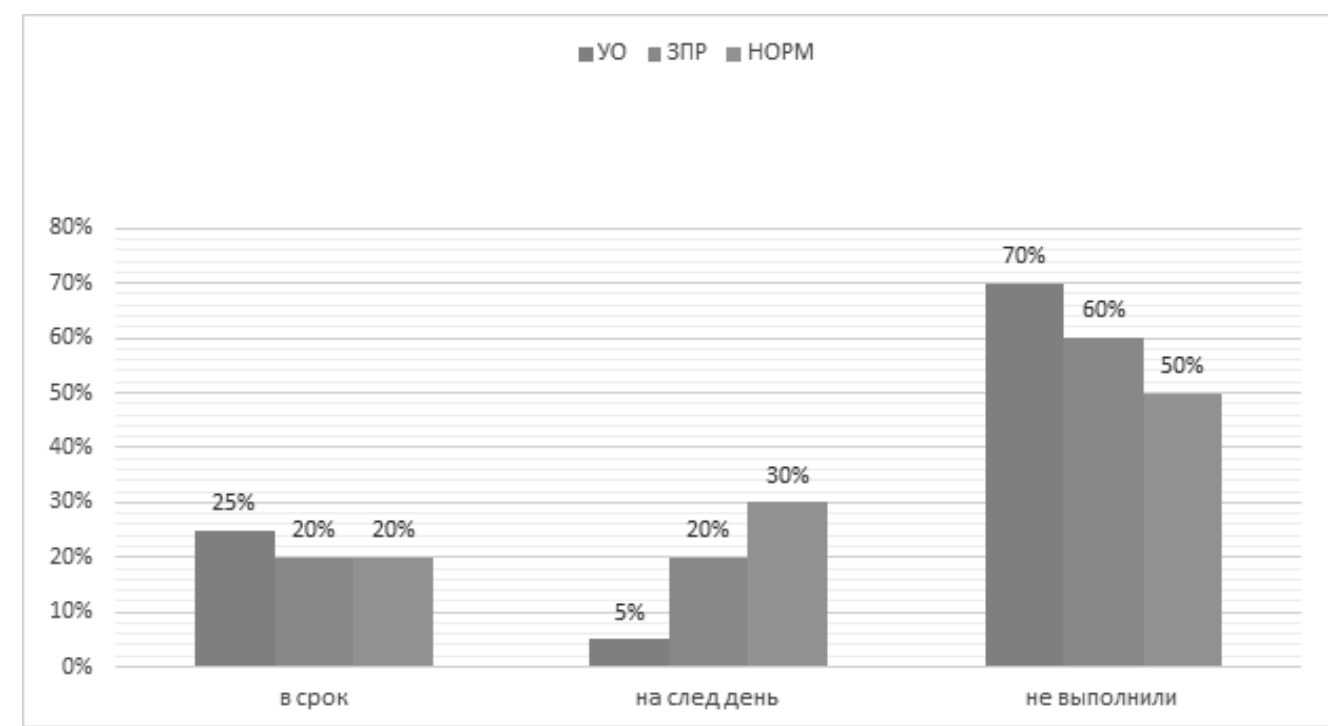

Рис. 1. Показатели проявления ответственности по методике «Задание с пятницы на понедельник». 


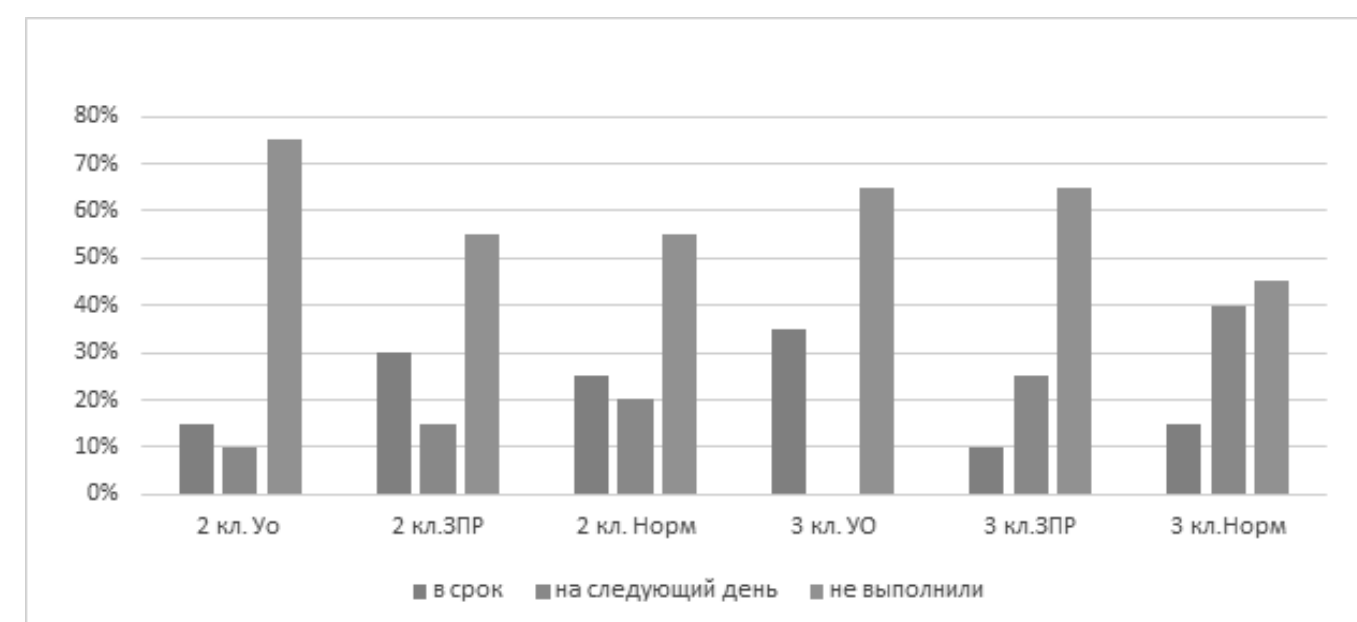

Рис. 2. Проявления ответственности по методике «Задания с пятницы на понедельник» в зависимости от класса обучения степени выраженности дефекта

мостоятельного ответственного выполнения задания заметно повышается у умственно отсталых учащихся - до 35\%, тогда как у детей с задержкой психического развития - падает до 10\%, а у нормально развивающихся детей - до 15\%. Можно говорить о том, что дети, выполнившие задание в срок, понимают значимость и важность выполнения просьб или заданий, эмоционально переживают и выполняют школьные обязанности, серьёзно относятся к требованиям взрослого. Причем проявление ответственного и самостоятельного выполнения задания повышается к третьему классу лишь у умственно отсталых школьников.

Среди учащихся, которые не принесли и не выполнили задание в срок, отмечались различной степени выраженности проявления эмоциональных переживаний. При этом у умственно отсталых школьников переживания не имели внешнего эмоционального выражения и заметной эмоциональной окраски. Свое невыполнение задания они объясняли следующим образом: «я забыл», «не знаю почему, не сделал», «мне не напомнили: Вы/мама». У детей с задержкой психического развития переживания были более насыщены и выражены эмоционально, чаще носили оправдательный характер: «я приготовил, но забыл, принесу в следующий раз», «а можно я принесу завтра?», «я не записал в дневник, поэтому забыл». У нормально развивающихся младших школьников можно было наблюдать ярко выраженные эмоциональные переживания, в которых отражались эмоции страха и вины, они также искали способы выхода из сложившейся ситуации - «что теперь делать?», «я запишу в дневник, чтобы не забыть завтра», «я теперь не сделаю то, что надо». Дети молча садились, были грустными, заметно переживали, спрашивали у своих одноклассников, могут ли они поделиться принесенными журналами.

Тем не менее, выполнившие задание на следующий день составили небольшой процент: всего 5\% умственно отсталых второклассников, а из третьеклассников данной категории детей никто не выполнил задание на следующий день. Среди детей контрольных групп, процент выполнивших задание в третьем классе возрастает: $25 \%$ учащихся с задержкой психического развития и 40\% нормально развивающихся младших школьников. Тогда как учащихся вторых классов, выполнивших задание на второй день, было несколько меньше (20\% и 30\% соответственно).

В число вовсе не выполнивших задание вошли нормально развивающиеся младшие школьники - 50\%, дети с задержкой психического развития - $60 \%$, умственно отсталые школьники -70\%.

Таким образом, анализ данных проведенного исследования позволяет сделать выводы о том, что:

- самостоятельное ответственное поведение младших школьников является недостаточно сформированным у них качеством. Дети могут переживать по поводу невыполнения задания взрослого, однако, несмотря на это, не всегда берут ответственность за результаты своей деятельности на себя, склонны оправдывать своё невыполнение рядом внешних причин;

- у умственно отсталых младших школьников мотивационный компонент при проявлении социально ответственного поведения в начальной школе находится на стадии формирования, имеет тенденцию к повышению проявления ответственного отношения к выполняемой деятельности. В целом, умственно отсталые школьники не стремятся к проявлению самостоятельности при выполнении какой-либо деятельности, их эмоциональные переживания при невыполнении задания не выражены, что связано с конкретностью их мышления и снижением критичности к 
результатам своей деятельности. Им необходимо ориентироваться на мнение, поддержку и контроль со стороны родителей или педагога. Они нуждаются в объединении со взрослыми, что помогает им усвоить начальные формы социальной ответственности и постепенно наращивать у них потенциал самостоятельности и ответственности. При этом сами родители должны стать участниками команды психолого-педагогическо- го сопровождения. Определяющую роль в такой команде играет психолог образовательного учреждения, раскрывающий и для самих родителей роль социальной ответственности в процессе социальной адаптации детей, содержание ее возрастных параметров, а также определяющий вместе с родителями средства, методы и приемы воспитания у детей ответственности и ответственного поведения.

\section{ЛИТЕРАТУРА}

1. Абульханова-Славская К.А. Стратегия жизни. М.: Мысль, 1991. - 299с.

2. Абульханова-Славская, К.А. Проблема исследования индивидуального сознания [Текст] / К.А. Абдульханова-Славская, М.И. Воловикова, В.А. Елисеев // Психологический журнал. - 1991, № 4. - С. 27-40.

3. Абульханова-Славская, К.А. Типология личности и гуманистический подход [Текст] / К.А. Абдульханова-Славская // Гуманистические проблемы психологической теории. - М., 1995. - С. 27-48.

4. Богданова Т.Г. Влияние внутрисемейных отношений на развитие личности глухих младших школьников / Т.Г.Богданова, Н.В. Мазурова // Дефектология : научно-теоретический и методический журнал / ред. В.И. Лубовский. - 1998. - №3 1998. - С. 40-44.

5. Божович Л.И. Избранные психологические труды: Пробл. формирования личности / Л.И. Божович; Под ред. Д.И. Фельдштейна. - М.: Междунар. пед. акад., 1995. -209 с.

6. Божович Л.И. Личность и ее формирование в детском возрасте. Психологическое исследование [Текст] / Л.И. Божович. - М. : Просвещение, $1968 .-464$ с.

7. Выготский Л.С. Педагогическая психология. - М., 2006., с.22

8. Климова, К.А. О формировании ответственности у детей 6-7 лет [Текст] / К.А. Климова // Формирование коллективных взаимоотношений у детей старшего дошкольного возраста. - М., 1968. - 353 с. 41

9. Матюхина М.В., Ярикова С.Г. К изучению ответственности как свойства целостной личности школьника // Теоретико-методологические основы учебновоспитательного процесса в школе и вузе. Волгоград, 1984. - С.115-129.

10. Морозкина Т.В. Формирование внутренней ответственности (на материале дежурства школьников по классу): дис. ... канд. психол. наук. - Москва, 1984.

11. Сидорова Т.Н. Исследование особенностей когнитивного и поведенческого компонентов социальной ответственности // Психологические условия формирования социальной ответственности школьников. - М., 1987. С. 51-54

12. Сорокоумова Е.А., Молостова Н.Ю., Ферапонтова М.В. Психолого педагогические аспекты становления ответственности младшего школьника поколения Z // Педагогика и психология образования. - 2017. - №1. - С. 146-153.

с Феоктистова Юлия Сергеевна (yulla13@mail.ru). 